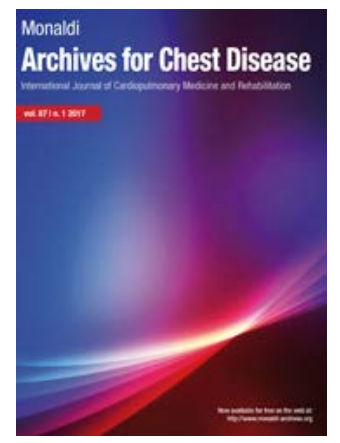

Monaldi Archives for Chest Disease

eISSN 2532-5264

https://www.monaldi-archives.org/

Publisher's Disclaimer. E-publishing ahead of print is increasingly important for the rapid dissemination of science. The Monaldi Archives for Chest Disease is, therefore, Epublishing PDF files of an early version of manuscripts that undergone a regular peer review and have been accepted for publication, but have not been through the copyediting, typesetting, pagination and proofreading processes, which may lead to differences between this version and the final one.

The final version of the manuscript will then appear on a regular issue of the journal. E-publishing of this PDF file has been approved by the authors.

Monaldi Arch Chest Dis 2021 [Online ahead of print]

To cite this Article:

Daverio M, Tinè M, Spagnolo P. The milky way. doi: 10.4081/monaldi.2021.1856

(C) the Author(s), 2021

Licensee PAGEPress, Italy 


\section{The milky way}

\section{Matteo Daverio, Mariaenrica Tinè, Paolo Spagnolo}

Respiratory disease Unit, Department of Cardiac, Thoracic, Vascular Sciences and Public Health, University of Padua, Italy

Corresponding author: Mariaenrica Tinè, Department of Cardio-Thoraco-Vascular Sciences and Public Health, University of Padua, Via Giustiniani 3, 35128 Padova, Italy. E-mail:

mariaenrica.tine@gmail.com

Key words: Chylothorax, Superior vena cava syndrome, pleural effusion

Authors' contribution: MD, MT, contributed to conception and writing of the manuscript; PS, revisited and corrected the manuscript. All the authors have read and approved the final version of the manuscript and agreed to be accountable for all aspects of the work in ensuring that questions related to the accuracy or integrity of any part of the work are appropriately investigated and resolved.

Conflict of interest: The Authors declare no conflict of interest relating to the study.

Funding: No funding support was taken for the conduct of the study.

Informed consent: Written informed consent for publication was obtained.

\footnotetext{
Abstract

Mediastinal masses may present with signs and symptoms due to either compression of mediastinal structures or systemic effects of the underling disease. The present case highlights the advantages of interventional pulmonology in the diagnosis of lymphoma as a cause of chylothorax and superior vena cava syndrome.
} 


\section{Introduction}

Chylothorax is a rare condition that consists of the collection of chyle in the pleural space secondary to the damage of the thoracic duct. We present the case of a woman with a chylous pleural effusion who was admitted with acute respiratory failure and superior vena cava syndrome. The diagnosis was made by interventional pulmonology procedures.

\section{Case Report}

A 58-year-old woman, current smoker (45 pack-years), presented with rapidly progressive shortness of breath and orthopnea. At hospital admission, she appeared dyspnoeic with a $\mathrm{SpO}_{2}$ of $86 \%$ on room air. Blood gas analysis showed hypoxemic respiratory failure $\left(\mathrm{pH} 7.45, \mathrm{pO}_{2} 49.2 \mathrm{mmHg}, \mathrm{pCO}_{2}\right.$ $31.3 \mathrm{mmHg}$, alveolar-arterial oxygen gradient $=62 \mathrm{mmHg}$ ). Her symptoms started about three weeks before when she noticed facial plethora with enlargement of the neck. A neck echography revealed only some reactive lymph nodes and some thyroid nodules. A few days later she perceived a changing in the voice and difficult swallowing. Moreover, she referred hyporexia and weight loss of $8 \mathrm{~kg}$ in the last two months. Her clinical history was relevant for asthma, breast cancer diagnosed in 2016 and treated with surgery plus radiotherapy, followed by Tamoxifen and lastly anastrozole. Given the clinical and radiological stability, the oncological follow-up had been suspended six months earlier. On physical examination, she appeared tachypnoeic (respiratory rate: 22) and tachycardic (heart rate: 130 ) with a blood pressure of $144 / 79 \mathrm{mmHg}$ and a body temperature of $36.5^{\circ} \mathrm{C}$. Her neck was enlarged and some small bilateral lymphadenopathy were present. Her face appeared cyanotic and the upper thorax revealed superficial vessels and telangiectasia (Figure 1). A dull percussion with decreased breath sounds were heard over the right lung field.

Serology and hematology revealed increased C-reactive protein levels $(46.40 \mathrm{mg} / \mathrm{l})$ with normal while blood cell count, renal and hepatic function. Chest X-ray and thoracic ultrasound showed a massive right pleural effusion. The patient underwent medical pleuroscopy with pleural biopsies. $3000 \mathrm{~mL}$ of latescent pleural fluid were drained and sent for analysis (Figure 2). The pleural surface did not display any macroscopic lesions, therefore twelve biopsies were randomly obtained from the lower parietal pleura. Chemical pleurodesis was performed and a $28 \mathrm{Ch}$ chest tube was placed. Once the pleural effusion had been removed, a contrast thorax-abdominal CT was requested. Imaging revealed an anterior mediastinal mass $(15 \times 13 \times 12 \mathrm{~cm})$ imprinting the trachea (Figure 3). Therefore, an Endobronchial Ultrasound-guided Transbronchial Needle Aspiration (EBUS-TBNA) of the mass was obtained. 
The effusion showed exudative features, such as $\mathrm{pH}$ 7.5; pleural fluid protein/serum protein ratio 0.67 (total protein $41 \mathrm{~g} / \mathrm{L}$ total serum protein $61 \mathrm{~g} / \mathrm{L}$ ); pleural fluid LDH/ serum LDH ratio 1.16 (pleural LDH $367 \mathrm{U} / \mathrm{L}$, serum LDH $315 \mathrm{U} / \mathrm{L}$ ) along with the presence of triglyceride $(806 \mathrm{mg} / \mathrm{dL})$. The observation of monoclonal B-lymphocytes proliferation suggested a diagnosis of chylothorax due to primary mediastinal large B-cell lymphoma. As expected in lymphoproliferative disease, pleural biopsies only revealed a rich inflammatory infiltrate with no atypical cells. In order to achieve a complete molecular characterization of the lymphoma, as required to initiate a targeted therapy, mediastinoscopy was performed. After few weeks of treatment, the chest tube was removed and the patient discharged with a scheduled outpatient follow-up.

\section{Discussion}

The case presented summarizes the possible manifestations of anterior mediastinal masses. The direct compression of normal mediastinal structures may cause shortness of breath, dysphagia, facial and upper extremity swelling along with superficial collateral venous pathways on the trunk, which is referred to as superior vena cava syndrome [1]. The presence of chylous effusion increased the dyspnoea and caused tachycardia. Chylothorax can be classified as traumatic or nontraumatic. Non-traumatic aetiologies include malignancy, sarcoidosis, retrosternal goitre, amyloidosis, superior vena cava thrombosis, benign tumours, congenital duct abnormalities and diseases of the lymph vessels such as yellow nail syndrome, lymphangioleiomyomatosis (LAM) and haemangiomatosis. Thoracic duct obstruction due to malignancy is the most common cause of nontraumatic chylothorax. Lymphoma is found in $70 \%$ of cases (non-Hodgkin's more often than Hodgkin's).

The effusion may be unilateral, either right (50\%) as in our patient, or left sided (33\%), or bilateral $(17 \%)$ based on the location of the leak. Damage to the duct above the fifth thoracic vertebra tends to result in a left sided effusion whereas damage to the duct below this level leads to a right sided effusion [2].

Non-milky appearance is a common presentation and may cause the diagnosis of chylothorax to be overlooked, as only half of the cases show the classical milky white fluid [3]. Lipoprotein analysis demonstrating the presence of chylomicrons in pleural fluid is the gold standard to diagnose chylothorax [4]. If this facility is not available, the diagnosis relies on the biochemical criterion introduced nearly 40 years ago by Staats et al. who found a pleural fluid triglyceride level greater than $110 \mathrm{mg} / \mathrm{dL}$ to be a relatively accurate marker for the presence of chylothorax [5]. 
The management of non-traumatic chylothorax includes the treatment of the underlying condition as well as measures aimed at replacing the nutrients loss with the chyle, draining large chylothoraces and parenteral feeding to reduce the chyle flow. Somatostatin and octreotide have proven useful in the conservative treatment of chylothorax. In cases of malignant chylothorax, chemical pleurodesis may offer an alternative option for patients that are too unwell for surgical closure of the chyle leak [6].

In our case, the patient underwent medical thoracoscopy, which was diagnostic and therapeutic by removing the chyle, thus rapidly improving respiratory symptoms [7]. Once reduced and analysed the pleural effusion, the patient underwent a chest CT scan which revealed the presence of a large anterior mediastinal mass. EBUS-TBNA of the mass suggested the diagnosis of primary mediastinal large B-cell lymphoma. Endobronchial approach of mediastinal masses is a promising diagnostic technique because of its safety and tolerability even in older patients and it is increasingly used to investigate mediastinal lymphomas [8]. Nonetheless, the samples obtained are generally small and the fibrotic process that often occurs in lymphomas may decrease the diagnostic sensitivity, particularly in the nodular sclerosing variant of Hodgkin lymphoma, which is characterized by its hypocellularity. It has been argued that the use of a bigger needle (22 vs $19 \mathrm{G}$ ) might increase diagnostic accuracy [9]. The limited data available confirm the low diagnostic yield of this procedure, although with an overall specificity approaching 100\% [10]. Overall, surgical biopsy, which allows complete morphological, cytogenetic, immunophenotypical and molecular analysis, is recommended by current guidelines [11].

Indeed, our patient underwent mediastinoscopy without complications, although this procedure has a higher mortality than EBUS-TBNA $(0.2 \%$ vs $0.01 \%)$ and is particularly complicated in patients who have previously treated with mediastinal radiotherapy [9].

\section{Conclusions}

We presented a case of chylothorax secondary to primary mediastinal B-cell lymphoma. Owing to its safety and tolerability, endobronchial ultrasound-guided transbronchial needle aspiration may represent a useful diagnostic tool in selected patients, although its diagnostic yield remains suboptimal. 


\section{References}

1. Rice TW, Rodriguez RM, Light RW. The superior vena cava syndrome: Clinical characteristics and evolving etiology. Medicine 2006;85:37-42.

2. McGrath EE, Blades Z, Anderson PB. Chylothorax: Aetiology, diagnosis and therapeutic options. Respir Med 2010;104:1-8.

3. Rahman NM, Chapman SJ, Davies RJO. Pleural effusion: A structured approach to care. $\mathrm{Br}$ Med Bull 2004;72:31-47.

4. Maldonado F, Hawkins FJ, Daniels CE et al. Pleural fluid characteristics of chylothorax. Mayo Clin Proc 2009;84:129-33.

5. Staats BA, Ellefson RD, Budahn LL, et al. The lipoprotein profile of chylous and nonchylous pleural effusions. Mayo Clin Proc 1980;55:700-4.

6. O'callaghan AM, Mead GM. Chylothorax in lymphoma: Mechanisms and management. Ann Oncol 1995;6:603-8.

7. Mares DC, Mathur PN. Medical thoracoscopic talc pleurodesis for chylothorax due to lymphoma: A case series. Chest 1998;114:731-5.

8. Gandotra S, Dotson T, Lamar Z, er al. Endobronchial Ultrasound transbronchial needle aspiration for the diagnosis of lymphoma. J Bronchol Interv Pulmonol 2018;25:97-102.

9. Lim CE, Steinfort DP, Irving LB. Diagnostic performance of 19-gauge endobronchial ultrasound-guided transbronchial needle aspiration (EBUS-TBNA) in suspected lymphoma: A prospective cohort study. Clin Respi. J 2020;14:800-5.

10. Labarca G, Sierra-Ruiz M, Kheir F et al. Diagnostic accuracy of endobronchial ultrasound transbronchial needle aspiration in lymphoma a systematic review and meta-analysis. Ann Am Thor Soc 2019;16:1432-9.

11. Vitolo U, Seymour JF, Martelli M et al. Extranodal diffuse large B-cell lymphoma (DLBCL) and primary mediastinal B-cell lymphoma: ESMO clinical practice guidelines for diagnosis, treatment and follow-up. Ann Oncol 2016;27:91-102. 


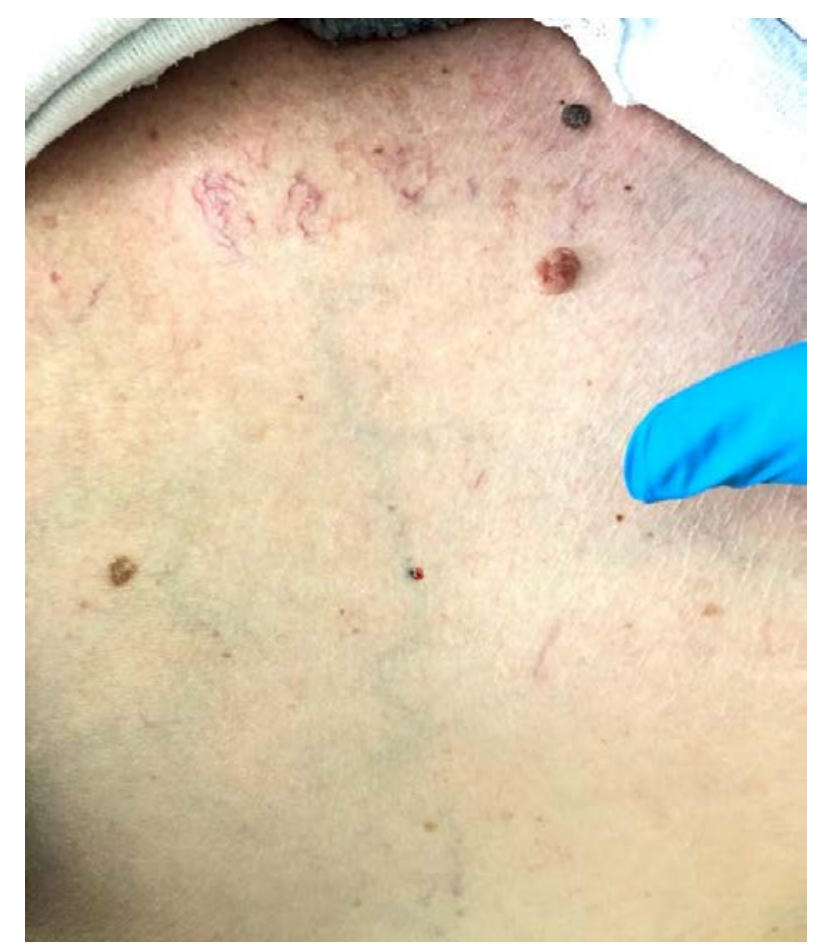

Figure 1. Superficial collateral venous pathways and angiectasias along the anterior trunk.

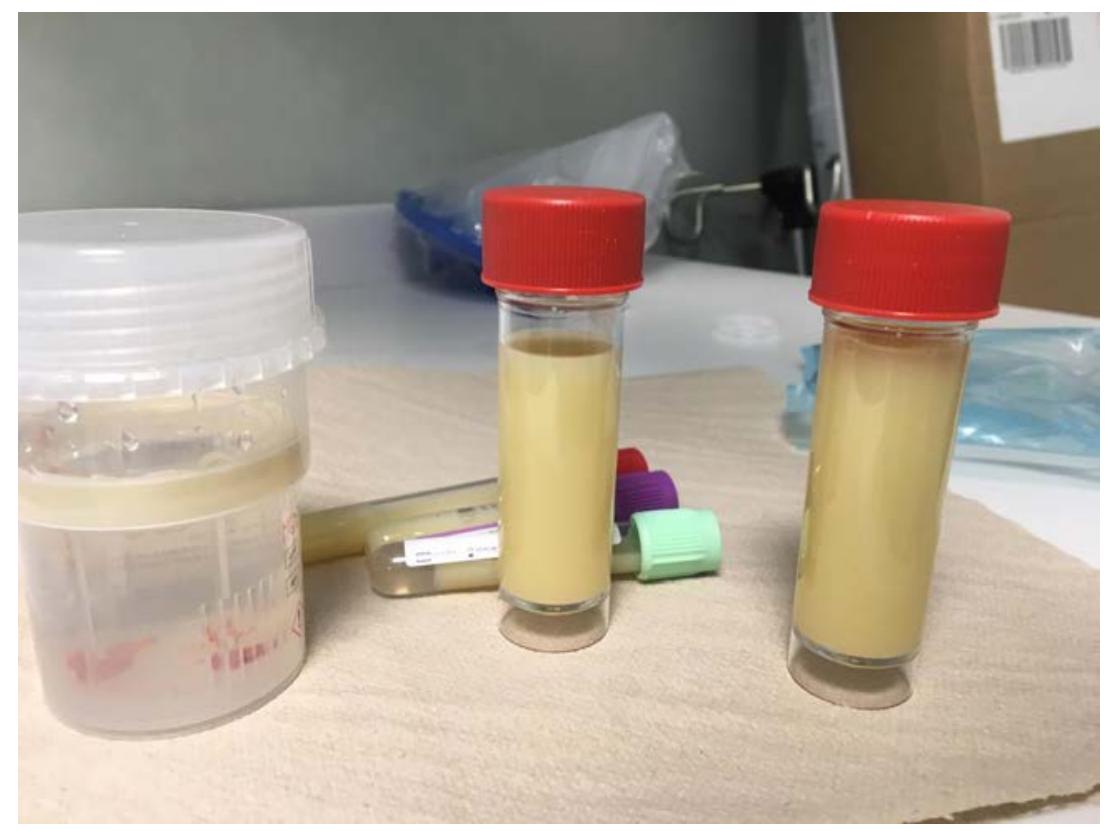

Figure 2. Pleural biopsies (on the left) and chylous effusion. 


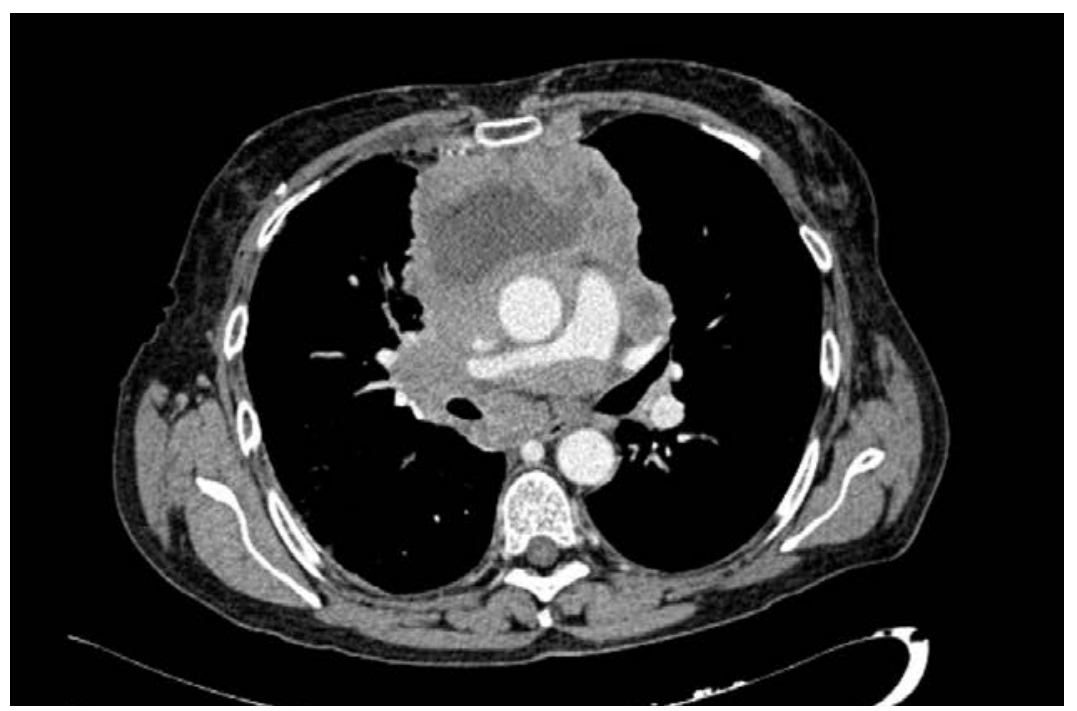

Figure 3. CT-scan showing the mediastinal mass and enlarged mediastinal lymph nodes. 